\title{
Effects of Passive Exposure to Tobacco, Socioeconomic Status and a Family History of Essential Hypertension on Lipid Profiles in Children
}

\author{
Akin Işcan, MD, B. Sami Uyanik,* MD, \\ Nureddin Vurgun, MD, Aydin EcE, MD, \\ and M. Ramazan Yı̈̆rTơ̆LU,* MD
}

\section{SUMMARY}

There is abundant evidence that the atherosclerotic process begins in childhood. Dyslipidemia is a major risk factor for atherosclerosis in adults and children. In the present study, we measured serum lipoprotein concentrations in 194 healthy children aged between 4 to 14 years. Children were grouped according to the sociocconomic status of the families, family history of essential hypertension and passive tobacco exposure. The values of total cholesterol, low density lipoprotein cholesterol and the ratio of total cholesterol/high density lipoprotein cholesterol in the low socioeconomic group were found to be significantly higher than the values obtained for the middle-high socioeconomic group. The values of total cholesterol, low density lipoprotein cholesterol, the ratio of total cholesterol/high density lipoprotein cholesterol and low density lipoprotein cholesterol/high density lipoprotein cholesterol in the passive smoker group were found to be significantly higher than those of the nonsmoker group. But, the socioeconomic level in the passive smoker group was found to be significantly lower than that of the nonsmoker group, and therefore, the impact of passivc smoking on the scrum lipids in children was related to socioeconomic status. A significant difference in terms of blood lipid fractions between the groups with and that without a family history of essential hypertension was not found.

These results suggest that passive smoking and lower socioeconomic status are important risk factors for cardiovascular heart disease, while a positive family history of essential hypertension is not an important risk factor. (Jpn Heart J 1996; 37: 917-923)

Key words: Child Lipoproteins Passive smoking Sociocconomic level Family history of essential hypertension

T $\mathrm{T}$ is well known that there is a strong relationship between coronary artery disease and some lipid fractions including total cholesterol (TC), triglycerides

From the Departments of Pediatrics and *Bochemistry, Faculty of Medicine, University of Celal Bayar, Manisa, Turkey

Address for correspondence: Akın Işcan, MD, P.O. BOX 106, 45100 Manisa, Turkey.

Received for publication February 13, 1996.

Accepted March 13, 1996. 
(TG), high density lipoprotein cholesterol (HDL-C) and low density lipoprotein cholesterol (LDL-C) concentrations. In addition, cigarette smoking is one of the cardiovascular risk factors as are obesity, hypertension, diabetes mellitus, etc. ${ }^{1-6)}$ Although cigarette smoking is associated with changes in plasma lipid and lipoprotein levels, it is unknown whether or not passive smoking is associated with an alteration in lipid profile of children or not. ${ }^{5-7)}$ Its relationship to passive smoking as well as active smoking has implications for pediatric atherosclerosis prevention. ${ }^{8,9)}$ For this reason we aimed to investigate the relationship of passive smoking to lipid profile in healthy children.

In the last decade several intervention studies have shown that dietary modifications produce changes in blood lipid levels in children, it is also a well known fact that dietary components and blood lipids are associated with socioeconomic status. ${ }^{(0-16)}$ The other purpose of this work was to study the relations between socioeconomic status and values for serum lipids in children.

There is a significant relationship between hypertension and blood lipid profile in adults. ${ }^{17-20)}$ Results of previous studies ${ }^{21,22)}$ indicated significant associations between parental history of hypertension and childhood blood pressure levels. The relationship between family history of essential hypertension and serum lipid concentrations in children was also evaluated in the study.

\section{Materials and Methods}

The experimental population consisted of 194 children, aged from 4 to 14 years. The children were examined by the same physician throughout the study. None of the children had any symptoms and signs of hypertension, hypercholesterolemia, abnormal blood pressure or obesity. They were not receiving any long-term medical treatment. Body weight, height, a family history of essential hypertension and passive exposure to tobacco were recorded. Parental education level was selected as the measure of socioeconomic status because it does not change. ${ }^{14,23)}$ Body mass index, weight/height ${ }^{2}$, was used as an obesity index. After a 12 hour fast, blood samples were obtained for TC, HDL-C and TG. The sera were frozen at $-20^{\circ} \mathrm{C}$ until analyzed. TC and TG were determined by enzymatic-calorimetric methods (Mitsubishi Z 818 autoanalyzer). HDL-G was measured after precipitation with magnesium-dextransulphate. Low density lipoprotein cholesterol was calculated using the standard formula (Friedwald formula): LDL-C $=\mathrm{TC}-\mathrm{HDL}-\mathrm{C}-\mathrm{TG} / 5$. Intraassay $\mathrm{CV} \%$ values for lipid tests were less than 7.

Two-sample independent groups $t$ test and chi-square test were used for statistical evaluation. 


\section{Results}

Baseline clinical characteristics and lipid values of groups appear in Tables I-IV.

No significant differences were found in terms of age, sex and the value of BMI between the middle-high socioeconomic level and the low socioeconomic level groups (Table I) or between the passive smoker group and the nonsmoker group (Table III). Also, there was no those significant difference in terms of these parameters between children with and those without a family history of essential

Table I. Baseline Clinical Characteristics and Lipid Values (Mean \pm SD) of Children Grouped According to Socioeconomic Level

\begin{tabular}{lccl}
\hline & \multicolumn{2}{c}{ Socioeconomic level } & \\
\cline { 2 - 3 } & $\begin{array}{c}\text { Low } \\
(n=11)\end{array}$ & $\begin{array}{c}\text { Middle-high } \\
(n=83)\end{array}$ & \\
\hline Age (year) & $9.3 \pm 3.1$ & $8.7 \pm 3.2$ & NS \\
Sex (Female/Male) & $53 / 58$ & $35 / 48$ & NS \\
Passive smoker/Non smoker & $76 / 35$ & $39 / 44$ & $p<0.01$ \\
BMI $\left(\mathrm{kg} / \mathrm{m}^{2}\right)$ & $16.8 \pm 2.4$ & $17.0 \pm 3.3$ & NS \\
Lipids & & & \\
TC $(\mathrm{mmol} / l)$ & $3.90 \pm 0.56$ & $3.67 \pm 0.55$ & $p<0.01$ \\
TG $(\mathrm{mmol} / l)$ & $1.16 \pm 0.36$ & $1.06 \pm 0.36$ & NS \\
HDL-C (mmol/l) & $1.22 \pm 0.1$ & $1.22 \pm 0.17$ & NS \\
LDL-C (mmol/l) & $2.13 \pm 0.55$ & $1.96 \pm 0.54$ & $p<0.05$ \\
TC/HDL-C & $3.25 \pm 0.63$ & $3.05 \pm 0.55$ & $p<0.05$ \\
LDL-C/HDL-C & $1.79 \pm 0.56$ & $1.64 \pm 0.51$ & NS \\
\hline
\end{tabular}

NS: Not significant

Table II. Lipid Parameters (Mean $\pm S D$ ) in Children Grouped According to Smoking Exposure in the Low and Middle-high Socioeconomic Levels

\begin{tabular}{|c|c|c|c|c|c|c|}
\hline & \multicolumn{6}{|c|}{ Socioeconomic level } \\
\hline & \multicolumn{2}{|c|}{ Low } & \multicolumn{2}{|c|}{ Middle-high } & \multicolumn{2}{|c|}{ Significance } \\
\hline & $\begin{array}{l}\text { Passive smoker } \\
\quad(n=76)\end{array}$ & $\begin{array}{c}\text { Nonsmoker } \\
(n=35)\end{array}$ & $\begin{array}{l}\text { Passive smoker } \\
\quad(n=39)\end{array}$ & $\begin{array}{c}\text { Nonsmoker } \\
(n=44)\end{array}$ & (1) & (2) \\
\hline Age (year) & $9.5 \pm 3.0$ & $9.1 \pm 3.4$ & $8.7 \pm 3.0$ & $8.7 \pm 3.4$ & NS & NS \\
\hline Sex (female/male) & $35 / 41$ & $18 / 17$ & $17 / 22$ & $18 / 26$ & NS & NS \\
\hline $\mathrm{BMI}\left(\mathrm{kg} / \mathrm{m}^{2}\right)$ & $16.6+2.3$ & $17.3 \pm 2.6$ & $17.2 \pm 3.6$ & $16.9 \pm 3.2$ & NS & NS \\
\hline TG $(\mathrm{mmol} / \mathrm{l})$ & $3.95 \pm 0.55$ & $3.81 \pm 0.60$ & $3.74 \pm 0.56$ & $3.60 \pm 0.54$ & NS & NS \\
\hline $\mathrm{TG}(\mathrm{mmol} / \mathrm{l})$ & $1.16 \pm 0.35$ & $1.16 \pm 0.38$ & $1.03 \pm 0.38$ & $1.09 \pm 0.34$ & NS & NS \\
\hline $\mathrm{HDL} \mathrm{C}(\mathrm{mmol} / \mathrm{l})$ & $1.21 \pm 0.17$ & $1.26 \pm 0.17$ & $1.22 \pm 0.14$ & $1.22 \pm 0.19$ & NS & NS \\
\hline LDL-C $(\mathrm{mmol} / \mathrm{l})$ & $2.21 \pm 0.50$ & $1.96 \pm 0.63$ & $2.06 \pm 0.52$ & $1.87 \pm 0.55$ & $p<0.05$ & NS \\
\hline TC/HDL-C & $3.33 \pm 0.61$ & $3.08 \pm 0.65$ & $3.11 \pm 0.55$ & $2.99 \pm 0.55$ & NS & NS \\
\hline LDL-C/HDL-C & $1.88 \pm 0.53$ & $1.59 \pm 0.59$ & $1.71 \pm 0.49$ & $1.57 \pm 0.52$ & $p<0.05$ & NS \\
\hline
\end{tabular}

(1) Significance between passive smoker and nonsmoker groups in the low socioeconomic level. (2) Significance between passive smoker and nonsmoker groups in the middle-high socioeconomic level. NS: Not significant. 
Table III. Baseline Clinical Characteristics and Lipid Values (Mean \pm SD) of Children Grouped According to Smoking Exposure

\begin{tabular}{lccc}
\hline & \multicolumn{2}{c}{ Groups } & \multirow{2}{*}{ Significance } \\
\cline { 2 - 3 } & $\begin{array}{c}\text { Passive smoker } \\
(n=115)\end{array}$ & $\begin{array}{c}\text { Nonsmoker } \\
(n=79)\end{array}$ & \\
\hline Age (year) & $9.2 \pm 3.0$ & $8.9 \pm 3.4$ & NS \\
Sex (female/male) & $52 / 63$ & $36 / 43$ & NS \\
Socioeconomic level (Middle-high/low) & $39 / 76$ & $44 / 35$ & $p<0.01$ \\
BMI $\left(\mathrm{kg} / \mathrm{m}^{2}\right)$ & $16.8 \pm 2.8$ & $17.1 \pm 2.9$ & NS \\
Lipids & & & \\
TC (mmol/l) & $3.88 \pm 0.56$ & $3.69 \pm 0.57$ & $p<0.05$ \\
TG (mmol/l) & $1.12 \pm 0.36$ & $1.12 \pm 0.36$ & NS \\
HDL-C (mmol/l) & $1.21 \pm 0.16$ & $1.24 \pm 0.18$ & NS \\
LDL-C (mmol/l) & $2.16 \pm 0.51$ & $1.91 \pm 0.59$ & $p<0.01$ \\
TC/HDL-C & $3.26 \pm 0.59$ & $3.03 \pm 0.59$ & $p=0.01$ \\
LDL-C/HDL-C & $1.82 \pm 0.52$ & $1.58 \pm 0.55$ & $p<0.01$ \\
\hline
\end{tabular}

NS: Not significant

Table IV. Baseline Clinical Characteristics and Lipid Values (Mean \pm SD) of Children Grouped According to Family History of Essential Hypertension

\begin{tabular}{lccc}
\hline & \multicolumn{2}{c}{ Family history of essential hypertension } & \\
\cline { 2 - 3 } & $\begin{array}{c}\text { Present } \\
(n=51)\end{array}$ & $\begin{array}{c}\text { Absent } \\
(n=143)\end{array}$ & \\
\hline Age (year) & $9.2 \pm 3.3$ & $9.0 \pm 3.1$ & NS \\
Sex (female/male) & $24 / 27$ & $64 / 79$ & NS \\
BMI (kg/m ${ }^{2}$ ) & $17.2 \pm 2.7$ & $16.8 \pm 2.9$ & NS \\
Passive smoker/nonsmoker & $27 / 24$ & $88 / 55$ & NS \\
Socioeconomic level (Middle-high/low) & $22 / 29$ & $61 / 82$ & NS \\
Lipids & & & \\
TC (mmol/t) & $3.83 \pm 0.55$ & $3.79 \pm 0.58$ & NS \\
TG (mmol/l) & $1.13 \pm 0.37$ & $1.11 \pm 0.36$ & NS \\
HDL-C (mmol/ $/$ ) & $1.22 \pm 0.16$ & $1.22 \pm 0.17$ & NS \\
LDL-G (mmol/t) & $2.09 \pm 0.54$ & $2.05 \pm 0.56$ & NS \\
TC/HDL-C & $3.19 \pm 0.57$ & $3.16 \pm 0.61$ & NS \\
LDL-C/HDL-C & $1.75 \pm 0.53$ & $1.72 \pm 0.55$ & NS \\
\hline
\end{tabular}

NS: Not significant

hypertension (Table IV). The passive smoker/nonsmoker ratio in the low socioeconomic level group was significantly higher than that of the middle-high socioeconomic level group (Table I). Also, the socioeconomic level was found to be significantly lower in the passive smoker group than in that of the nonsmokers (Table III).

Mean $( \pm \mathrm{SD})$ values for fasting serum lipid fractions $(T C$, HDL-C, LDL-C, TG) and the ratios of TC/HDL-C and LDL-C/HDL-C in ten different subgroups appear in Tables I-IV. The values for TC, LDL-C, and TC/HDL-C ratio in the low socioeconomic level group were found to be significantly higher than the values obtained for the middle-high socioeconomic level group. Signif- 
cant differences were not found in HDL-C and TG concentrations between these two groups (Table I).

Mean \pm SD values for fasting serum lipid fractions (TC, HDL-C, LDL-C and TG) and TC/HDL-C and LDL-C/HDL-G ratios in the middle-high socioeconomic level group and in the low socioeconomic level group according to smoking exposure are listed in Table II. No significant differences in blood lipid profiles were found between the passive smoker group with middle-high socioeconomic level and the nonsmoker group with middle-high socioeconomic level. The values for LDL-C and LDL-C/HDL-G ratio in the passive smoker group with low socioeconomic level were found to be significantly higher than the values obtained for the nonsmoker group with low socioeconomic level. No significant differences were observed in the TC, HDL-C and TG concentrations and TC/HDL-C ratio between these two groups (Table II).

The values of TC and LDL-C and the ratios of TG/HDL-G and LDL-C/ HDL-C in the passive smoker group were found to be significantly higher than that of nonsmokers. No significant differences were observed in the HDL-C and TG concentrations between these two groups (Table III).

A significant difference was not found in the values of blood lipid fractions between the group with and that without a family history of essential hypertension (Table IV).

\section{Discussion}

A relationship between socioeconomic factors and lipid profile in both adults and children has been demonstrated. ${ }^{24,26-28)}$ We noted a more atherogenic lipid profile in children belonging to low socioeconomic status contrary to other studies. ${ }^{13-16)}$ Environmental differences between populations as well as study design may influence the results of various studies. We also observed that hard margarine was consumed excessively by the children with low socioeconomic status. A higher incidence of smoking exposure in children with low socioeconomic status was also found in the study (Table I).

There are only a few studie ${ }^{22,25)}$ which investigated the blood lipid profiles in children with and that without family history of essential hypertension. No significant differences in serum concentrations of TC, HDL-C, LDL-C and TG, and TC/HDL-C, LDL-C/HDL-C ratios between the children with and those without a family. history of essential hypertension were found. These results are all consistent with prior investigations. ${ }^{22,25)}$ It was concluded that family history of essential hypertension could not identify children with higher levels of atherogenic lipoprotein.

Many investigators have found that cigarette smoking is associated with an 
elevated TC and ratio of TC/HDL-C, a lowered HDL-C, elevated LDL-C and LDL-C/HDL-C ratio. ${ }^{6-9,29-31)}$ In our study, it was found that passive exposure to tobacco smoke was associated with both a higher concentration of TC and LDL$\mathrm{C}$ and a higher ratio of TC/HDL-C and LDL-C/HDL-C. These changes may be associated with the socioeconomic status of children because the socioeconomic level in the passive smoker group was found to be significantly lower than that of the nonsmoker group (Table III). The value of LDL-C and the ratio of LDL-C/HDL-C in the passive smoker group with low socioeconomic status were found to be significantly higher than that of the nonsmoker group with low socioeconomic status. No significant difference was found in terms of serum lipid and lipoprotein values between the passive smoker group with middle-high socioeconomic status and the nonsmoker group with middle-high socioeconomic status (Table II). Therefore, we concluded that the impact of smoking exposure on serum lipids in children was related to socioeconomic status.

The passive exposure of children, especially those with low socioeconomic status, to tobacco smoke may be associated with an increased risk of developing coronary heart disease in the future, and therefore these children should be followed-up for atherosclerosis prevention.

\section{References}

1. Kwiterovich PO. Detection and treatment of elevated blood lipids and other risk factors for coronary artery disease in youth. Ann NY Acad Sci 1995; 17: 313-40.

2. Leon AS. Age and other predictors of coronary heart disease. Med Sci Sports Exerc 1987; 19: $159-67$.

3. Criqui MH. Epidemiology of atherosclerosis: an updated overview. Am J Cardiol 1986; 57: 18C-23C.

4. Kohn R. Smoking and passive smoking- one of the major factors threatening the health and life of the younger generation and adults. Cesk Pediatr 1992; 47:686-7.

5. Joseph F, Ronald S, Ruth AE, et al. Passive smoking alters lipid profiles in adolescents. Pediatrics 1991; 88: 259-64.

6. American Heart Association. Active and passive tobacco exposure: a serious pediatric health problem. A statement from the Committee on Atherosclerosis and Hypertension in Children, Council on Cardiovascular Disease in the Young. Circulation 1994; 90: 2581-90.

7. Botash AS, Kavey KW, Emm N, Jones D. Cardiovascular risk factors in Native American Children. NJ State J Med 1992; 92: 378-81.

8. Sanches BM, Gonzales RA, Ruiz JC, et al. Smoking and apolipoproteins in adolescents. J Adoles Health 1992; 13: 524-7.

9. Woodward M, Bolton SG, Tunstall PH. Deficient health knowledge, diet and other life styles in smokers: is a multifactorial approach required? Prev Med 1994; 23: 354-61.

10. Variarten E, Puska P, Pietinen $P$, et al. Effects of dietary fat modifications on serum lipids and blood pressure in children. Acta Paediatr Scand 1986; 75: 396-401.

11. Walter HS, Hofman A, Vaughan RD, et al. Modifications of risk factors for coronary heart disease; five year results of a school-based intervention trial. N Engl J Med 1988; 318: 1093-100.

12. Sanchez BM, Gonzalez RA, Baeze J, et al. Diet therapy for hypercholesterolemia in children and adolescents: a followup. Arch Pediatr Adolesc Med 1994; 148: 28-32.

13. Wajid AS, Buch NA, Masood H. Serum lipid profile in Kashmiri children. Indian J Physiol Pharmacol 1995; 39: 55-8.

14. Simons IA, Simons J, Magnus P, Bennet SA. Education level and coronary risk factors in Australians. 
Med J Aust 1986; 145: 446-50.

15. Poletto L, Pezzotto S, Morini J. Blood lipid associations in 18 year old men. Rev Saude Publica 1992; 26: 316-20.

16. Arias Alyarez MA, Sanchez Bayle M, Gonzalez Vergaz A, et al. The effect of socioeconomic level on the lipid pattern in children and adolescents. Rev Sanid Hig Publica Madr 1993; 67: 47-56.

17. Bilgin $R$, Donma $O$, Günday V, Sagliker $Y$, Lipid profile and lipoproteins in essential hypertension. Tr J of Medical Sciences 1994; 20: 81-3.

18. Fuh MMT, Shieh SM, Wu DA, Chen TDI, Reaven GM. Abnormalities of carbohydrate and lipid metabolism in patients with hypertension. Arch Intern Med 1987; 147: 1035-8.

19. MacMahan SW, MacDonald GT, Blacket RB. Plasma lipoprotcin levels in treated and untreated hypertensive men and women. Atherosclerosis 1985; 5: 391-6.

20. Catalano M, Aronica A, Carzaniga G, Seregni R, Libretti A. Serum lipids and apolipoproteins in patients with essential hypertension. Atherosclerosis 1991; 87: 17-22.

21. Feinleib M, Garrison RJ. The contribution of family studies to the partitioning of population variation in blood pressure. In: Sing CF, Skolnik M, editors. Genetic Analysis of Common Diseases. New York: AR Liss, 1979: 653.

22. Charles LS, Larry SW, David SF, et al. The relationship between parental history of vascular disease and cardiovascular disease risk factors in children: Bogalusa Heart Study. Am J Epidemiol 1985; 122: 762-71.

23. Diehl AK, Fuller JU, Mattock MB, Salter AM, El Gohari R, Keen $\mathbf{H}$. The relationship of high density lipoprotein subfractions to alcohol consumption, other lifestyle factors, and coronary heart disease. Atherosclerosis 1988; 69: 145-53.

24. Kaplan GA, Keil JE. Socioeconomic factors and cardiovascular disease: a review of the literature. Circulation 1993; 88 (4pt 1): 1973-98.

25. Dawber TR. The Framingham Study. Cambridge: Harvard University Press, 1980: 91-141.

26. Leupker RV, Rosamond WD, Murphy $\mathrm{R}$, et al. Socioeconomic status and coronary heart disease risk factor trends. The Minnesota Heart Survey. Circulation 1993; 88 (5pt 1): 2172-79.

27. Dos Santos JE, Pressler WW, Viteri F, Preto R. Risk factors of coronary artery disease and their relationships with dietetic and social variables. Arq Bras Cardiol 1994; 63: 371-5,

28. Jaglal SB, Goel V. Social inequity in risk of coronary artery disease in Ontario. Can.J Cardiol 1994; 10: 439-43.

29. Halfon ST, Green MS, Heiss G. Smoking status and lipid levels in adults of different ethnic origins: the Jerusalem Lipid Research Clinic Program. Int J Epidemiol 1984; 13: 177-83.

30. Maskowitz WB, Masteller MM, Schieken RM, et al. Lipoprotein and oxygen transport alterations in passive smoking pre-adolescents children: the MCV twin study. Circulation 1990; 81: 586-92.

31. Misawa K, Matsuki H, Kasuga H, Yokoyoma H, Hinohara S. An epidemiological study on the relationship among HDL-cholesterol, smoking and obesity. Nippon Eiseigaku- Zasshi 1989; 44: 725-32. 